\title{
Héctor Libertella, de la narración al ensayo. Una poética de la ficción teórica
}

\section{Héctor Libertella, from narration to essay. A poetics of theoretical fiction}

\author{
Silvana López \\ Universidad de Buenos Aires, Argentina
}

\begin{abstract}
Resumen: Inscripta en la genealogía de Macedonio Fernández, Jorge Luis Borges y José Lezama Lima, la escritura de Héctor Libertella es una poética de la reescritura, de la exhibición desaforada de que la literatura es una operación de lectura, recorte y apropiación de lo ya escrito, y de la literaturización de esa lectura. Esas operaciones son el caballo de Troya con las que Libertella trastorna los conceptos del realismo y las categorías de la metafísica proponiendo una literatura de la huella, descentrada, que se disemina y desvía a una multiplicidad sin dejarse reducir a una forma con un sentido único. Denunciados por Nietzsche como construcciones, la lengua, el sujeto, la forma, el tiempo, el espacio, son perturbados por la escritura libertelliana mediante maniobras citativas, intertextuales y transgenéricas.
\end{abstract}

Palabras claves: Libertella, reescritura, huella, realismo, metafísica.

Abstract: Belonging to the genealogy of Macedonio Fernández, Jorge Luis Borges and José Lezama Lima, the writing of Héctor Libertella is a poetry of rewriting, of the outrageous exhibition that literature is an operation of reading, cutting and appropriation of what has already been written and of the literaturization of that reading. These operations are the Trojan horse with which Libertella disrupts the concepts of realism and the categories of metaphysics proposing a literature of the trace, decentered, that spreads and redirects to a diversity without being reduced to a form with a unique sense. Denounced by Nietzsche as constructions, the language, the subject, the form, the time, the space, are disturbed by the Libertellian writing by means of citations, intertextual and transgeneric maneuvers.

Keywords: Libertella, Rewriting, Trace, Realism, Metaphysics.

Recibido: 05 de marzo de 2017

Aceptado: 23 de abril de 2017 
LIFTING. La reescritura sería el arte de darle naturalidad a lo muy trabajado[...] ese trabajo siempre dejará un resto de artificio, como la sensación de un cuerpo orgánico, pero con huesos o varillas de metal adentro [...] un robot que lleva a cuestas el viejo fantasma llamado literatura.

Héctor Libertella, El árbol de Saussure

Hablemos de reescribir, actividad que exacerba la condición fantasma del escritor. Su antología personal, por ejemplo, ya no vendrá de libros, ni tendrán sus Obras Completas rastro o huella de obra alguna.

Héctor Libertella, Zettel

\section{Cero}

1 emorias de un semidios, El árbol de Saussure, La arquitectura Zettel, de Héctor Libertella, publicados entre 1998 y 2010, conforman una red textual en la que la reescritura aparece como un hilo conductor que domina su poética. Si la reescritura es un proceso que retoma o vuelve sobre la productividad de un texto anterior para configurar otro que despliega una organización y espacialidad diferente, estableciendo interrupciones y persistencias con la textualidad sobre la que ha operado, la poética de Héctor Libertella puede ser leída como un complejo entramado de tematizaciones de las diversas instancias de ese proceso de reescritura. El escribir aparece como una modalidad exhibida del reescribir, particularidad que le imprime a los textos una productividad con múltiples entradas y salidas que conlleva la puesta en escena de una escritura de la huella, de una escritura como proceso en el que se encuentran implicados: la lectura, la escritura y la exhibición de esa lectura/ 
escritura; los procedimientos formales y temáticos de transformación de los lenguajes en materia literaria; la condición fantasma del escritor; la configuración de una poética que se muestra como una literatura de segundo grado y que, en su artificialidad, pivotea entre la ficción, la crítica y la teoría, entre la tradición y la fundición de la letra antigua, entre la literatura latinoamericana y la literatura legitimada por el canon occidental, entre el mercado literario y la mónada o pequeño cepo gramatical encerrejado en el que late desnuda la literatura. Perturbar la escritura del realismo y de las representaciones del logos, "matar" al autor, soltarle la mano al lector y dejar que la escritura, fragmentaria, discurra por la página en blanco para trastornar el libro y su paginación romántica también.

Una poética de una literatura de segundo grado puede leerse desde la primera novela publicada de Héctor Libertella, El camino de los hiperbóreos ${ }^{1}$ debido a que la escritura libertelliana se constituye a partir de un entramado de textos provenientes de la biblioteca, de la tradición y de la reescritura de sus propios textos, insistiendo en la "incesancia" 2 de la huella, en el rastro y en la retención de una presencia siempre diferida. Ese proceso de reescritura se realiza a través de diversas operaciones, en algunos casos, se expande el

${ }^{1}$ El camino de los hiperbóreos gana el Premio Paidós de Novela, en 1968. Héctor Libertella cuenta en La arquitectura del fantasma. Una autobiografia (2006) que escribió sus novelas Tarde para llorar y Agentes de la venganza, entre los once y catorce ańos; otros textos comienzan a circular bajo la impronta efervescente de la década del sesenta, cuando estudia Letras en la Universidad Nacional del Sur, en Bahía Blanca (Argentina), también participa de distintas experiencias en el teatro, el cine y la radio mientras envía sus cuentos y novelas a concursos literarios. Los premios obtenidos -Paidós, Monte Ávila, Juan Rulfo- arman una cartografía de sus producciones y la inscripción en más de un registro (cuento, novela, poema, relato) que expone su literatura.

${ }^{2}$ Concepto desarrollado por Noé Jitrik en "La palabra que no cesa", como aquella palabra, giro o construcción que en su retorno, sin cesar, se repiten, desplazando el lugar del significado para significar en un adentro y afuera de la semiosis. SYC, núm. 3, Buenos Aires, Septiembre 1992. 
motivo narrativo de una frase a un texto de varias páginas (la serie Magallanes que culmina en El lugar que no está ahí, de 2006); en otros, el motivo o fragmento trasmigra de textualidad en textualidad (desplazamientos que se reúnen en Zettel, de 2009), perturbando su pertenencia a un género en particular. Así, la poética de Libertella despliega una cartografía en la que retorna lo "ya-escrito" (Barthes, 1997) atravesado por múltiples desvíos y fugas como si su escritura insistiera en el trazo de un centro descentrado en continuo desplazamiento produciendo una maniobra distintiva: el encuentro de la repetición y de la variación de motivos constructivos y temáticos que producen condensaciones y expansiones. Con la impronta de lo propio y de lo ya leído y ya escrito (porque Libertella pone en funcionamiento una teoría de la lectura que no se relaciona con la interpretación sino con la transformación del sujeto lector) el texto se construye como un tejido de huellas, de reescrituras, cuyas operaciones citativas, intertextuales y transgenéricas se plasman en la cinta de la sintaxis mediante maniobras de apropiación, injerto, trasplante, transmigración, transcripción, repetición, desvío, desplazamiento.

Si bien la literatura puede ser pensada como un "proceso", la poética de Libertella tematiza y exhibe esas marcas. En El susurro del Lenguaje, Roland Barthes reflexiona sobre el concepto del "moderno escribir" preguntándose desde cuándo se habrá comenzado a usar el verbo "escribir" como intransitivo, ya que el paso del escritor de ser "el que escribe algo a ser el que escribe, de manera absoluta" constituye un cambio de mentalidad debido a que el uso intransitivo de "escribir" convierte el libro o el texto en un objeto particular. La noción de diátesis, más que la intransitividad, es la que puede dar la clave de ese "moderno escribir" porque designa - en una correlación con la voz activa, media y pasiva- la manera en que el sujeto (escritor) se ve afectado por el proceso (escritura), concluyen- 
do que es la voz media la que se corresponde por completo con el escribir de la modernidad:

escribir, hoy día, es constituirse en el centro de la palabra, es efectuar la escritura afectándose a sí mismo, es coincidir acción y afección, es dejar al que escribe dentro de la escritura, no ha título de sujeto psicológico [...] sino a título de agente de la acción (Barthes, 1987).

El escritor permanece de ese modo, siempre, en el interior del proceso, como sucede con el narrador proustiano que "tan sólo existe cuando está escribiendo" (Barthes, 1987).

Esa figura de escritor es dominante en la poética libertelliana, su práctica escrituraria se pliega y se despliega en ese interior, en los textos inacabadamente reescritos. Literatura y vida, cuerpo y texto escribiéndose incesantemente. La poética de Libertella problematiza esa "manera" del "absoluto" que indica Barthes debido a que la escritura de Libertella deshace esa categoría cuya posible trascendencia se desplaza a la figura de un escritor singular y a una escritura en la incesancia del devenir. La letra escrita-leída libertelliana no se detiene, sigue en proceso, y cada tanto una versión de ese flujo escriturario se envía a la imprenta y se publica como texto autónomo que establece contactos y diferencias con esa textualidad. ${ }^{3}$ El escritor que es Libertella, "encuadernado en la continuidad inesperada de su leer" (como dice Macedonio Fernández) y de su escribir (agrego yo), es figurado en referencias y ensayos críticos de sus amigos: en el prólogo de Marcelo Damiani o los ensayos de Ricardo Strafacce y Laura Estrin, en El efecto Libertella (2010), o en

${ }^{3}$ Para una lectura de las diversas modalidades de reescritura de Héctor Libertella, ver López, Silvana, "El árbol, la huella y el fragmento. Escritura y lenguaje en los textos de Héctor Libertella” en Revista Letral, http://revistaseug.ugr.es/ index.php/letral/article/view/3785 
el texto bellamente escrito de Rafael Cipollini en Libertella/Lamborghini. La escriturallimite (2016):

1. Libertella entendía al libro como un soporte de escritura que sólo concluía con la muerte del escritor. Se había enamorado de la anécdota del pintor nabí Pierre Bonnard, que le conté cierta vez y que menciona al pasar en la página 88 de El árbol de Saussure "obras de padecer una interminable ejecución: muy reescritas". Prestemos atención a los términos: interminable, ejecución, padecimiento. Y por supuesto, reescritura. Hasta los pintores reescriben cuando pintan. Sucede que cuando Bonnard tenía setenta años, sus pinturas eran propiedad del Louvre. Lo que solía hacer entonces, era hacerse pasar por pintor aficionado que deseaba hacer copias de las obras del museo, se mezclaba entre los aprendices con su caballete, y se ubicaba cerca de sus cuadros sin que nadie supiera que precisamente él era el autor. Entonces, cuando los guardianes de sala se distraían, se acercaba a sus propias obras de juventud y las retocaba. Esto le traía problemas con los guardias de sala, que sorprendían in fraganti a un viejo interviniendo obras de arte. A Libertella le encantaba la anécdota. Él sabía que, mientras estuviera vivo, sus libros seguirían mutando, como las pinturas de Bonnard. La imprenta era sólo una estación, una escala -en todos los sentidos del término- Un libro era el resultado de una sucesión de actos nunca menor a: 1. mecanografiar (la mecánica música del tipeo), 2. corregir a mano, volver a mecanografiar, volver a escribir a mano, mandar a imprenta. Retomar el libro impreso -esto no necesariamente era inmediato-. Volvía sobre el libro para reescribirlo, ya no para corregirlo. De acuerdo a su mecánica, la corrección, en un momento bastante temprano, devenía reescritura. Este paso entre corrección y reescritura es fundamental (66).

El proceso de escritor y escritura reescribiéndose, que trastorna la idea de manuscrito porque no hay corrección sino reescritura, se tematiza, como se lee en los epígrafes de este ensayo (las citas del 
El árbol de Saussure y de Zettel) o en las cuatro cartas dirigidas a su amigo, el escritor cubano Lorenzo García Vega, en La arquitectura del fantasma. Una autobiografía, en las que se lee al escritor inmerso en el proceso de lectura, escritura y reescritura, maniobrando y articulando los artefactos literarios, como Clive Langham, el protagonista del film Providence, realizado por el actor John Gielgud:

Mi respetado y nunca bien ponderado Lorenzo. La cosa está. Es una enorme laguna, y a sus orillas un bebé muy viejo toma vacaciones, toma vacaciones a orillas de una laguna mental porque es muy viejo, el bebé. Y bebe. Todo el tiempo bebe un chablis frío, como sir John Gielgud en Providence (primera carta, 2006).

Escribo -como te anuncié- la biografía del viejo que pude haber sido [...] Hoy es el día exacto de mi cumpleaños, y no sé si estoy atrás o delante de lo que escribo (tercera carta, 2006; las itálicas son mías).

Así que acá estoy, aislado desde hace ocho o nueve meses reescribiendo y achicando simultáneamente doce libros y eliminando otros tantos. Rumbo al impalpable cero. Encerrado en una pieza de dos metros por tres. Un amigo chistoso observaba ayer que yo camino mi pathos por una celda tan apretada como la horma de mis zapatos.

Mirá, Lorenzo, es un salto sin red abajo [...] Vos me entendés, es un viaje sólo de ida y al final te espera sir John Gielgud con un chablis en la mano (cuarta carta, 2006; las itálicas son mía).

\section{Uno}

En el proceso de lectura-escritura-reescritura hay estaciones que se presentan a la lectura crítica como textualidades bisagras en las que pueden distinguirse diversas instancias: uno, la operación de 
reescritura con la que comienza el "pro-yecto" ${ }^{4}$ literario: El camino de los hiperbóreos (1968) es la reescritura de La Hibridez (1965), novela nunca publicada; ${ }^{5}$ dos, la dominancia de la reescritura de sus propios textos a partir de ¡Cavernícolas! (1985) que tiene a la parodia ${ }^{6}$ como procedimiento constructivo e inicia la aparición de

${ }^{4}$ Considero la idea de "obra" como "pro-yecto", con un guion en el medio, para recuperar el sentido de obra que va hacia adelante, que se va haciendo, como propone Roland Barthes en La preparación de la novela, en el que reflexiona sobre la novela no como género literario histórico sino como "toda obra donde hay trascendencia del egotismo" (227). Al estudiar las operaciones del "yo del escritor", dice que la novela no es la expresión de "una forma literaria determinada" sino "una forma de escritura capaz de trascender la escritura misma, de ampliar la obra hasta la expresión total -aunque dominada- del Yo Ideal, del Yo Imaginario", en esa dirección, sostiene Barthes, la obra es un "Pro-yecto", es una "obra hacia delante" (228), que se plasma mediante el impulso del trabajo y la voluntad personal del escritor.

${ }^{5}$ El texto de 1968 no coincide cronológicamente con la temporalidad de los primeros escritos de Héctor Libertella, pues ya tiene publicado y premiado cuentos como "Argumento capital" de 1964 en Nueve cuentos laureados; La hibridez (1965), obtiene la mención especial Primera Plana de Novela Argentina, concurso que se declara desierto, motivo por el cual la novela nunca se publica permitiéndole a Libertella reescribirla con el título El camino de los hiperbóreos. La reescritura de La hibridez "cuaja" un texto en el que es posible leer el comienzo del pro-yecto libertelliano porque condensa una "carga" que "descarga" y en su "inflexión ordenadora" (Jitrik, 2000) exhibe un conjunto de procedimientos y motivos que, resignificados desde la perspectiva de los últimos textos libertellianos, permiten reconocer las marcas de una poética que singulariza su escritura. En marzo de 2017, saldrá el primer tomo de las obras completas de Héctor Libertella al cuidado de Rafael Cipollini. La versión de La hibridez que se publicará es la que ha sido reconstruida siguiendo las indicaciones dejadas por Libertella (no el original de 1965); el texto está compuesto por: El camino de los hiperbóreos, fragmentos de Aventura de los miticistas y otros fragmentos leídos en otros textos.

${ }^{6}$ La parodia considerada como maniobra de lectura ligada al horizonte intertextual y a los efectos que provoca en los campos de legibilidad (ver Noé Jitrik en "Rehabilitación de la parodia", en La parodia en literatura latinoamericana, 1993). Mi hipótesis se asienta sobre la idea que la parodia como procedi- 
una poética del blanco de la página y el adelgazamiento de los textos mediante una espacialización que resuena en el "impalpable cero" de la autobiografía, o en el "volver a cero y empezar de nuevo" (1971) como "en la mismísima boca de la serpiente que se muerde la cola" (1971) de Aventuras de los miticistas.

El camino de los hiperbóreos es el "punto adecuado", el "suitable point” (Said, 1985), cuya estructuración exhibe las marcas con las que Libertella comienza su pro-yecto literario, operaciones que con repeticiones y variaciones se mantienen constantes en su poética. El texto es una novela de artista que exhibe una voluntad y un querer ser escritor:

Héctor Cudemo circulaba dopado por las calles de Buenos Aires, se sentía como el mensajero de oscuras deidades nocturnas, llevaba sobre su espalda el peso de una triste genealogía de aburridos [...] Sentía incomprensibles todas esas charlatanerías de los gordos poetas oficiales, y andaba por la ciudad con los dolores de parto, embarazado, cargando en su seno un enorme embrión de libro [...] (Libertella, 1968).

Ese embrión es el libro que finalmente se lee, cuya escena de escritura se ha elidido mientras teje en el envés de la "genealogía de aburridos", un texto plural, multilingüe que problematiza las voces de enunciación y las categorías de tiempo y espacio, ${ }^{7}$ exhibe proce-

miento provoca el repliegue de la letra en un incesante proceso de reescritura. ¡Cavernicolas! está compuesto por tres relatos: "La Historia de Historias de Antonio de Pigafetta" que parodia La primera vuelta al mundo del cronista Antonio de Pigafetta y de la figura de Fernando de Magallanes; "La leyenda de Jorge Bonino" parodia la biografía del performer argentino del mismo nombre y una entrevista a Bonino realizada por Tamara Kamenszain; el tercer relato, "Nínive", parodia las aventuras de Hormuzd Rassam, el descubridor de las tablillas asirias descifradas por George Smith como la Epopeya de Gilgamesh.

${ }^{7}$ El narrador de la novela es, por momentos, un narrador en primera persona y se identifica como Héctor Cudemo pero, al fragmento siguiente o a la línea 
dimientos "citativos", "intertextuales" y "transgenéricos" (dibujos

siguiente, se desplaza a un narrador en tercera pocas veces identificable. Esa problematización también se exhibe en el tratamiento de la temporalidad y del espacio. El texto se desplaza del presente al pasado y del pasado, confusamente, al presente. El relato del pasado, los viajes, las experiencias artísticas de Cudemo están enmarcados por la incrustación de pequeños fragmentos en los que Héctor narra y delira desde su cuarto de enfermo, escena con la que se abre la novela. Esa operación de escandir el relato impide precisar si los viajes (hacia el oeste, a Buenos Aires, a la Pampa, por toda la Argentina y América) suceden y son recuerdos del pasado, o son viajes mentales. Se suma a ello la profusión de experiencias narradas, su repetición y expansión, las idas y vueltas, que, sin fechar, impiden organizar cronológicamente los hechos narrados. Un ejemplo de ello se lee en la segunda parte de la novela, "Viajes de H. Cudemo"; ahí, el protagonista se encuentra en su habitación de enfermo, veinte líneas más abajo, cuenta: "Y ahí empezó el largo peregrinaje" (122), a continuación, narra un viaje por la Pampa hacia Buenos Aires, "el chiquero de la Iluminación", el fragmento se cierra con Héctor nuevamente en la habitación agregando "Y ahora... me hundo en el bosque" (126) del que sale en la Tercera Parte de la novela: "Salimos del bosque, un poco con la idea de haber profanado nuestro orden" (243); entre el ingreso y la salida de ese bosque se injertaron relatos, experiencias de viajes, reflexiones metaliterarias, fragmentos de obras de teatro, entre otros. Asimismo, Roland Barthes, en $S / Z$, señala que el trenzado de las voces "en la masa perspectiva de lo ya escrito desoriginan la enunciación" (16).

${ }^{8}$ La palabra (el texto), dice Julia Kristeva en 1966, "es un cruce de palabras (de textos) en el que se lee al menos otra palabra (texto)" y es Bajtin el que introduce en la teoría literaria que "todo texto se construye como mosaico de citas, todo texto es absorción y transformación de otro", instalando la noción de intertextualidad. La citación es un fenómeno de la intertextualidad, en ese sentido, Michel Rifatterre, en "La Trace de l'intertexte", señala que la intertextualidad no se limita a la presencia de un texto en otro que apela a la memoria del lector sino que junto a la intertextualidad aleatoria hay una intertextualidad obligatoria que se presenta como una "presunción", una anomalía, como la sospecha de una significación latente, que perdida en el tiempo, la lectura actualiza. Por lo tanto, la citación no implica sólo la cita entre comillas o un cambio de tipografía, signos que señalan la operación de meta-enunciación que involucra el acto de citar, sino un trabajo de lectura -toda cita es en primer lugar una lectura y la lectura, una citación, sostiene Antoine Compagnon en La seconde main. Ou le travail de la citation-y una relación interdiscursiva de repetición - un enunciado 
y dispositivos de otros lenguajes provenientes del teatro, del cine, de la filosofía, de la música y de las artes plásticas). Una poética en la que la inventio se encuentra en la dispositio y, dispuesta en forma de fragmento," despliega lo "informe" y un arte conceptual, para perturbar los modos clásicos del narrar. Dos posiciones de escritor se infieren a partir de la novela, la del miticista, que viene a derribar el "libro oficial" como anota en la dedicatoria del hiperbóreo, a partir de la cita del dictus nietzschiano del título, ${ }^{10}$ metaposición que

repetido y una enunciación repitente- que tiende puentes de doble mano entre el texto citado y el texto inserto, en el que las citas que conforman la textualidad son, en muchos casos, sin entrecomillado y, no obstante, ya leídas. La citación se implica con la genericidad en tanto potencia transformadora que produce que un texto no reduplique su género sino que lo modifique. La migración de las citas de un texto/contexto a otros, en la idas y vueltas de sus tematizaciones, provoca movimientos de transgenericidad debido a que las citas insertas en un texto con un protocolo de lectura genérica, se deslocalizan y se injertan en otros textos que exhiben otra performatividad.

9 Señalan Lacoue- Labarthe y Nancy, en El absoluto literario, que la esencia del fragmento es la "individuación", en el sentido de indicador de un" proceso", de un "proyecto", que no funciona como programa ni como prospectiva, sino como "proyección inmediata de lo que, sin embargo, no acaba" (87). Por una parte, el espacio del fragmento, señala Maurice Blanchot, posibilita la sinergia entre la lectura y la escritura sin que una sustituye o privilegie a la otra ya que el fragmento reduplica la productividad de ambas debido a que "la ley de la una es el entredicho de la otra" (1994); por otra parte, y en la línea de la huella, el pensamiento del fragmento "dice el tiempo como eterna repetición", la repetición sin origen, repetición que es diferencia y diferencia "que, esencialmente, escribe" (Lacoue- Labarthe y Nancy, 2008).

${ }^{10}$ El camino de los hiperbóreos es una cita de El Anticristo. Maldición sobre el cristianismo de Friedrich Nietzsche y, sobre todo, es un modo de leer y de tomar posición frente a la literatura. El filósofo hiperbóreo es para Nietzsche un genealogista, un espíritu libre que "emplea el cuchillo" (Anticristo), también el martillo, para producir la "transvaloración de todos los valores", en el sentido de cambiar y sustituir unos valores por otros. Una posición crítica que con preguntas nuevas y "ojos nuevos" viene incluso a poner "en lugar de un error, otro distinto" (Genealogía). 
en el "moderno escribir", articula un repertorio de maniobras de fugas y desplazamientos, irreductibles, experimentales, que hacen estallar lo literario.

El comienzo del proyecto literario de Héctor Libertella con esa novela es notorio porque aparece cuando simultáneamente comienzan a circular en París las nuevas líneas de la crítica y la teoría. ${ }^{11}$ Entre 1965 y 1967, Libertella reescribe La Hibridez de cuya productividad resulta El camino de los hiperbóreos. En 1967,, ${ }^{12}$ mientras Libertella escribe una poética de la huella en El camino de los hiperbóreos, aparece De la gramatología de Jacques Derrida, que teoriza sobre la noción de huella, grama ó différance; ${ }^{13}$ en 1968 ,

${ }^{11}$ Surge el ideario de una época mediante la referencia al materialismo dialéctico y al psicoanálisis, teorías a partir de las cuales los integrantes de Tel Quel (Jacques Derrida, Michel Foucault, Roland Barthes, Julia Kristeva, Philipe Sollers) se apartan del estructuralismo, del existencialismo y, como tal, de la filosofía de la conciencia.

${ }^{12}$ El texto se abre in media res con el dibujo de un calendario del mes de Agosto de 1967 en el que se encuentran tachados los números hasta el 24, día de cumpleaños de Héctor Cudemo, el protagonista de la novela y también cumpleaños de Héctor Libertella, nacido el 24 de agosto de 1945. El tópico del viaje y el de la escritura y la vida, trae otra fecha: "Patria de aborígenes, tierra de flores, yo te sentí desde adentro y me hice un raro fulgor en los ojos [...]. El veintisiete de abril de mil novecientos sesenta y siete, a las cinco de la mańana, salimos con el brioso Carlitos, Sancho del alma, hacia los confines de la ciudad" (1968: 245). La intertextualidad con la generación beatniks así como con Adán Buenosayres de Leopoldo Marechal es ineludible.

${ }^{13}$ En De la gramatología, Jacques Derrida expone el concepto de "escritura" para deconstruir los principios de la metafísica de la presencia y del logocentrismo en tanto "metafísica de la escritura fonética" (1971: 7). A partir de la consideración de la lengua como forma (no sustancia) y como sistema de diferencias que formula Ferdinand de Saussure, en Curso de lingüistica general, Derrida especula una gramatología proponiendo los conceptos de "archi-escritura" como aquella escritura que no es la representación metafísica de la lengua hablada sino que se constituye como la condición de posibilidad del lenguaje, el trazo de la "différence" y el tejido de la "huella" concebido como una estructura y un movimiento que ya no se dejan pensar a partir de la oposición presencia/ausencia sino de 


\section{año de publicación de la novela, Roland Barthes publica la versión francesa de "La muerte del autor", en Mantéia. ${ }^{14}$ Una consonancia}

la différance que es la operación "sistemática de las diferencias, de las trazas de las diferencias, del espaciamiento por el que los elementos se relacionan unos con otros". Esas diferencias entre los elementos constituyen "textos, cadenas y sistemas de huellas" cuya diferencia "inaudita entre lo que aparece y el aparecer [...] es la condición de todas las otras diferencias, de todas las huellas y ella es ya una huella", un (no) origen y "origen de toda repetición" que "ningún concepto de la metafísica puede describirla [sic]" (Derrida, 1971). La huella no remite a un origen, ya que este "ni siquiera" se ha constituido, sino que el origen de la huella es otra huella y otra, en una deriva sin fin. No hay huella originaria, señala Derrida, "la huella (pura) es la diferencia [sic]. No depende de ninguna plenitud sensible, audible o visible, fónica o gráfica" (1971) siendo la huella "el origen absoluto del sentido en general. Lo cual equivale a decir, una vez más, que no hay origen absoluto del sentido en general [sic]" (1971) porque el lenguaje que la archi-escritura hace posible se desvía del logos, de la verdad, permaneciendo como un juego, un espacio-tiempo, de diferencias sin clausura.

14 "The death of the author" se publica en Aspen Magazine, núm. 5-6, 1967; la versión francesa en Matéia, núm. 5, 1968, recogido luego en El susurro del lenguaje (Barthes, 1984). En ese ensayo, Barthes problematiza la pregunta acerca de quién habla en el texto, enunciando la muerte del autor y el nacimiento del lector debido a la imposibilidad de origen de la enunciación ya que la escritura destruye toda voz y todo origen. El escritor moderno nace a la vez que su texto y no es en absoluto el sujeto cuyo predicado es el libro, afirma, al tiempo que retoma el concepto de Bajtin y Kristeva sobre el texto como "tejido de citas" y despliega la idea de no originalidad de la escritura. En el sentido de la huella derridiana, al no haber original, Barthes dice que el escritor sólo tiene el "poder de mezclar las escrituras" siendo el lector el que restituye, en su lectura, uno de los posibles sentidos de un texto que no cesa de producirlo. Estos conceptos se materializarán luego en la enunciación de una teoría del texto, en 1973, en "Texto (teoría del)" en el que Barthes formula sus especulaciones en torno al texto que ya no es un "producto" sino una "productividad" distinguiendo la "significación" (que pertenece al plano del producto, del enunciado, de la comunicación) del "trabajo significante" que pertenece al plano de la producción, de la enunciación, de la simbolización se llama "significancia" (Barthes, 2003). Publicado en Encyclopaedia Universalis, vol. 15, Paris, Encyclopaedia Universalis, Editeur; reunido en Roland Barthes, Variaciones sobre la escritura (2003). 
teórica que Libertella visibiliza años más tarde, en 1987, cuando, en la presentación de Los fulgores del simulacro de Nicolás Rosa, señala que mientras en Argentina se leía a Michel Foucault, a Roland Barthes, a Jacques Derrida, ellos estaban leyendo a Jorge Luis Borges y, por lo tanto (agrego yo), por las particularidades de la poética borgiana, las huellas de la luminosa escritura de Macedonio Fernández. La coincidencia es notoria porque con esa anécdota, Libertella fecha la productividad de la ficcionalización y la teorización de la confabulación literaria y de los procesos de lectura.

“Sería posible una teoría de la lectura que postule que Uno es la necesidad de traducir a Otro?” (2003: 79) se pregunta Libertella, en "Macedonio...¿un Borges al cuadrado?". La vampirización discursiva emparienta las poéticas de Borges y Macedonio, observa Julio Prieto, ${ }^{15}$ así como la inscripción traumática del yo autorial que agujerea el argumento o la ficción para sustituir "la univocidad del sentido" por la "plasticidad de la significación" (2007: 486); la operación en ambos casos es la "exapropiación"16, Macedonio lo hará mediante la práctica de una escritura por el lindero de "la

${ }^{15}$ Julio Prieto analiza minuciosamente los desplazamientos, fugas y re-colocaciones que Macedonio produce en la escritura de Borges y Borges en la de Macedonio. "La inquietante extrañeza de la autoría. Contrapunto, fugas y espectros del origen en Macedonio y Borges" en "Macedonio", Historia crítica de la literatura argentina (2007).

16 "En las transacciones textuales de Macedonio y Borges, como en toda escritura, hay contrabando y expropiación, hay nocturnidad y alevosía: ambos tienen algo de Dr. Jekyll a la vez que de Mr. Hyde. La extrañeza a la que me refiero tiene que ver más bien con lo que Derrida llama exapropiación (Espectros de Marx: 104): una dinámica de cuestionamiento de lo "apropiado" (en el doble sentido de lo "sustraído" y lo "pertinente"), de lo rutinariamente hecho "propio" - de lo "propio" debido a otro(s). En otras palabras, la extrañeza de estas escrituras empieza por el hecho de que ambas ponen en práctica un discurso que recubre a la vez que incesantemente recobra el espectro de una deuda" en "Viajeras razones'. Julio Prieto en "Metafísica y fantasía o el extraño caso de Macedonio y Borges" (Cahiers LI:RI:CO 1, 2006: 139-155). 
imposibilidad" y Borges, por una práctica de la "lectura como utopía”.

Una frase de música del pueblo me cantó una rumana y luego la he hallado diez veces en distintas obras y autores de los últimos cuatrocientos años. Es indudable que las cosas no comienzan; o no comienzan cuando se las inventan. $\mathrm{O}$ el mundo fue inventado antiguo (Macedonio Fernández, Museo de la novela de la eternal (2007: 488).

La crítica a la autoría, el presentar la escritura como si fuera de otro, el escribir la escritura del otro, el Pierre Menard de Borges o la cantante rumana de Macedonio apuntan a subrayar la imposibilidad del original y de la originalidad. De ese modo, lo propio no se suscribe a un autor sino depende de esa intrínseca relación entre lectura y escritura que potencia la cita, la alusión, el metatexto, las maniobras de apropiación y la reescritura que funcionan como condiciones de posibilidad al producir un texto.

En 1967 se publica, póstumamente, en Buenos Aires, la primera novela de Macedonio Fernández, Museo de la novela de la eterna. El escritor es para Libertella la recurrencia a un nombre en el que se apoyan lecturas y reflexiones críticas sobre la literatura argentina y latinoamericana; asimismo, la poética libertelliana exhibe el dispositivo de construcción de la novela en "capas". Éstas se insertan y diseminan entre una y otra textualidad junto a la implicación del lector/escritor en un trabajo de lectura/escritura como un "lento venir viniendo" más que como "una llegada". En ese sentido, aunque no puede considerarse los textos de Héctor Libertella como "una literatura de la nada", como señala Alicia Borinsky sobre Macedonio Fernández, comparten una galería de juegos "con el objeto de desenmascarar las ilusiones creadoras de la ficción". Sus juegos, agrega Borinsky, "son redes con una función estrictamente negativa: destruir toda lectura que no vea el texto 
como re-escritura de otra lectura" (Borinsky, 1975). Asimismo, el despliegue de distintos procedimientos libertellianos, que tornan los textos inestables tanto en sus aspectos genéricos como en la interpolación de la ficción con la teoría, la crítica y la autobiografía intelectual, traman una textualidad que puede definirse (en la línea de la poética macedoniana y, considerando el contexto de aparición, en los años sesenta, de El camino de los hiperbóreos) como literatura conceptual.

Libertella es lector de Borges, su literatura dialoga con la de Borges en los procedimientos de reescritura, en la literatura hecha de literatura y en la apropiación (traducción) de la literatura universal, así como también en la construcción de una biografía literaria que en el caso de Libertella, organizada en un linaje patrilíneo, se asienta sobre la idea de viaje, de motín o de desvío por error que desciende de los barcos y encalla en el "puerto más perdido del mundo": Ingeniero White- Bahía Blanca.

La huella Borges-Macedonio se da a leer en la escritura libertelliana. Palimpsesto, intertextualidad, crítica a la originalidad, inscripción del lector, estetización y ficción crítica de los lenguajes y saberes, literaturización y perturbación de la metafísica, ${ }^{17}$ resistencia a las formas estereotipadas de la institución literaria y a los discursos dominantes, el desvío de las falsas listas, los apócrifos,

17 "Borges y Macedonio tienden a alejarse de una cierta tradición del pensamiento occidental que desde Platón a Sartre apela a la literatura como discurso suplementario", afirma Julio Prieto, "el gesto de devaluar la metafísica y subordinarla a la literatura invierte con exactitud el hecho de que la literatura fantástica de Borges es fácilmente concebible como una ramificación de la metafísica de Macedonio. Pero lo que Borges tiene en común con Macedonio es la discontinuidad con esa tradición occidental de filosofía "literaria": en Borges lo ancilar es la metafísica, objeto de lúdica manipulación ficcional y en este sentido se diría que lo que comparte con Macedonio, más allá de una serie de "viajeras razones" metafísicas, es el deseo de inscribir un corte en una determinada tradición a partir de cierto modo de viajar entre filosofía y literatura (2007). 
constituyen un conjunto de operaciones de la genealogía BorgesMacedonio, las cuales han sido leídas tanto por Libertella, para tramar su poética, como por los franceses, para desplegar sus especulaciones en los años sesenta.

El camino de los hiperbóreos y la obra de Héctor Libertella puede ser leída bajo la impronta del "pensamiento de la huella", no en el sentido del despliegue de una especulación filosófica como la de Jacques Derrida ni la de Friedrich Nietzsche (la de Derrida también atravesada por la lectura de Nietzsche) sino en el de la inscripción de una escritura que exhibe los trazos de una teoría de la lectura, de operaciones de lectura y escritura del escritor, trazos que condensan maniobras de protensión y de retención, de anuncio y de recuerdo, de rastros que mortifican la idea de original. Libertella escribe sobre la huella de La Hibridez que remite a otra y a otra, a una cadena de huellas, que provenientes de la literatura y de otros lenguajes confluyen en El camino de los hiperbóreos. En algunos casos los rastros dejan sus marcas como sucede con las citas de Nietzsche, de Marechal, de la literatura de los beatniks, la lengua de los griegos o la tematización del pop y los happenings, que se leen en la novela, en otros permean cual fantasma que asedian y perturban al lector. Acaso ese sea el efecto que provoca el texto de 1965, nunca publicado como tal y del que sólo quedan algunos testimonios de su existencia en Primera Plana y en las palabras del escritor recogidas por Laura Estrin en el artículo de la revista Espacios, en el que Libertella confirma la reescritura de la novela.

El texto de 1968 es una exhibición desaforada de la literatura como fenómeno visual y del estrecho vínculo con el ojo, la mirada y la lectura. Esto se da por la multiplicidad de materiales, grafías, dibujos, lenguajes, que presenta y por el tratamiento de esos materiales: el dibujo, el poster, la foto, la grafía en minúscula, el cambio de tipografías, la invariancia de la disposición de la inscripción de la letra en el blanco de la página, escriben y perturban la sucesivi- 
dad del lenguaje, de la lectura y de la transcripción de la escritura fonética, eso que Derrida denomina "el modelo enigmático de la línea” (1971). El camino de los hiperbóreos reúne un conjunto de maniobras que Derrida, en De la gramatología, enuncia como trastornos al logos que se relacionan con un rasgo de la poética libertelliana. Libertella manifiesta, en La curiosidad impertinente, en la respuesta a Guillermo Saavedra acerca de su bibliomanía, un modo de pensar la literatura que no se imbrica con el logos sino que lo desvía:

se trata de cierta ancestral obsesión mía con la tipografía, la utopía del original perfecto [...] Para mí, el trabajo de escritor no termina con el hecho de encontrar palabras sino que continúa hasta el momento de fijarlas en un soporte de una manera determinada y determinante. La idea es dibujar letras más que escribirlas; concebir la escritura, al modo de los japoneses, como una pictografía. Esto es en mí una fijeza infantil; empecé a escribir mi primer libro a los 11 años y ese libro ya tenía esas pretensiones [...] la literatura es sobre todo un fenómeno visual. El ojo marca las condiciones de la lectura (Libertella, 1993; las itálicas son mías)

En De la gramatología, Derrida se detiene en las escrituras "no fonéticas" sobre las que reflexionó Hegel (a través del elogio de las escrituras "no fonéticas" de Liebniz como la jeroglífica) y toda una tradición filosófica. Derrida, que lee al autor de la Fenomenología del espiritu como el "último filósofo del libro y primer pensador de la escritura", ${ }^{18}$ indica que esas escrituras producen un desvío que amenaza la metafísica de la presencia.

${ }^{18}$ Según Derrida, Hegel resume la totalidad de la filosofía del logos y en el mismo gesto denuncia el ser fuera de sí del logos: la escritura es el fuera de sí, su exteriorización (1971). 
desde hace mucho tiempo sabemos que la escritura china o japonesa, que son masivamente no-fonéticas, han comportado desde muy temprano elementos fonéticos. Estos permanecieron estructuralmente dominados por el ideograma o el álgebra, y tenemos de esta manera el testimonio de un poderoso movimiento de civilización desenvolviéndose al margen de todo logocentrismo (1971).

No sólo los filósofos se sintieron atraídos por esas "escrituras no europeas", sostiene Derrida, Ezra Pound se fascinó con el ideograma chino, con el trabajo de Ernest Fenollosa, y su poética "irreductiblemente gráfica” junto con la de Stephane Mallarmé constituyeron la "primera ruptura de la más profunda tradición occidental" (1971) ya que provocaron un descentramiento en las categorías de la lengua y de la gramática de la episteme. $\mathrm{Al}$ romper "la línea" y espacializarse, Derrida señala que las escrituras "no fonéticas" describen "relaciones" y no "denominaciones" perturbando la sustancialidad y la metafísica de lo propio, de la palabra, del nombre, que exige el logocentrismo.

Hay que observar que la ruptura que lee Derrida no se produce en la filosofía ni en la ciencia sino en la literatura y en la escritura poética, organizando una tradición literaria que tiene incidencia en la literatura argentina de la que Libertella es lector. En esa dirección, Mallarmé es un "nombre propio" y una poética que recorre la poética libertelliana como un precursor velado y como una iteración que concluye en el epígrafe "Le monde est fair pour aboutir à un beau livre" ${ }^{19}$ que abre El lugar que no está ahi, texto que se publica en octubre de 2006, cuando muere Héctor Libertella.

${ }^{19}$ En una entrevista de Babel, marzo de 1991, Libertella cuenta que cita esa frase de Mallarmé con frecuencia pero al consultar con César Aira, ambos dudaron sobre ella y su transcripción, ya que la frase es una respuesta de Mallarmé a su entrevistador en una época que no había grabadores. Me interesa señalar que 
El camino de los hiperbóreos cruza las escrituras fonéticas con otras tipologías de inscripción provocando un modo de leer que perturba la linealidad. Esto sucede no sólo por la verticalización de la imágenes y dibujos que espacializan la escritura lineal y el blanco de la página, sino también por la dislocación de las voces de la enunciación y de las categorías de tiempo y espacio mediante maniobras de suspensión y de desvío. Así, la experiencia narrada o la argumentación reflexiva se desestabiliza, se ambigua, a la línea siguiente o al fragmento siguiente, o en algún espacio de la novela. En contraposición a la unidad, no hay intriga ni climax, se da a leer como múltiples inicios de experiencias o como una línea de viaje que marcha hacia delante y aunque se regresa al punto de partida, ese punto ya no es el mismo desde el que se parte. En continuo desplazamiento, la novela narra una ilación de experiencias haciéndose, pensándose, escribiéndose, desplazándose, contra toda economía, en una profusión de temas y motivos, de formas narrativas, de diagramas, de fotos, posters y dibujos. El dispositivo de escritura borra toda certeza e identificación de una "denominación"; el "nombre" se quiebra por la indeterminación de quien narra, por el trabajo de citación y por la yuxtaposición de letras de canciones, proverbios populares, guiones de cine y de teatro. Libertella escudriña el armazón formal y estético de los distintos lenguajes y archivos cuyas modulaciones formales, temáticas e iconográficas son citadas y narrativizadas en El camino de los hiperbóreos articulando un texto como un "mosaico de citas" cuya "significancia" fluye no sobre vías deterministas sino citacionales. Esto potencia la productividad textual y la impronta de la inventio en la dispositio, en la cinta de la sintaxis que permite la "mezcla", la fuga, el desvío, el delirio, la re-locación, para transformar la lengua y así desplegar un programa literario. La escritura de Héctor Libertella no remite,

aun sobre la duda y el desvío de esa cita, Libertella retoma e insiste en esa poética del Libro mallarmeano. 
por lo tanto, a un origen, a una linealidad, sino a los rastros en devenir de los lenguajes, que literaturizados, son puestos a jugar en una heterogeneidad inestable y diferida.

\section{Dos}

A medida que despliega su programa literario, Libertella irá teorizando sobre ese conjunto de procedimientos que exhibe la novela de 1968 que, en la búsqueda de encontrar una forma, se relaciona más con un 'cómo narrar' que con un 'qué narrar'.

Las maniobras de ficcionalización narrativa y de ficcionalización teórica, que en El camino de los hiperbóreos se leen en el narrar, se complejizan y se exhiben críticamente en Nueva escritura en Latinoamérica (1977) mediante maniobras de lectura y escritura que luego Libertella narrativiza en los tres relatos que conforman ¡Cavernicolas! (1985).

En el ensayo de 1977, Libertella especula sobre la literatura latinoamericana como un "cuerpo histórico" y, al mismo tiempo, hace ostensible su biblioteca, sus lecturas, sus modos de leer la literatura y de leer a los escritores latinoamericanos con los que trama su escritura. Figura de ese modo otra posición de escritor, debido a que toma distancia de la autorreferencialidad de la literatura argentina para citar, reflexionar, escribir, tramar, la literatura del continente latinoamericano. Se puede decir que Nueva escritura es una autobiografía de lecturas y, como tal, una exhibición desaforada del leer escribiendo, no con el soplo de las musas ni con la sonatina, sino con un trabajo de escritor, de un escritor que conoce la biblioteca y el entramado de las genealogías y que es transformado por esas lecturas ya que entrelaza con ellas su poética. Nueva escritura da a leer un conjunto de textos que aparecen entre 1965-1976 que "difieren" del conjunto de la literatura latinoamericana, textos denominados de "vanguardia" o "nueva escritura" debido a que exhiben 
una lectura activa de la tradición realizadas por un escritor llamado "cavernícola", que se apropia y reprocesa la tradición literaria, la incorpora críticamente y, sin negarla ni reprimirla, la reescribe, produciendo otro texto en el que, a puro artificio, los "elementos aparecen proyectados, aplastados, des-representados" (Libertella, 2008) en un nuevo espacio de escritura. Libertella indica en el "Apéndice" del ensayo que el cavernícola es el escritor crítico que trabaja contra la representación quitándole volumen a los elementos narrativos y entorpeciendo toda referencia. Esa instancia de lectura y reescritura da como resultado una "escritura de segundo grado" que penetra para destruir y borrar toda representación. Así, la novela se vuelve a escribir sobre "las partículas sueltas" de la biblioteca y en forma de fragmento mediante un dispositivo de vanguardia denominado "el juego de la novela aplastada" (Libertella, 2008).

El continente latinoamericano se concibe en el ensayo como una "piedra" que se escribe a partir de una mentalidad superpuesta: “¿indígena, europea, mestiza, grecolatina?” (Libertella, 2008) cuya sobredeterminación y superposición produce una literatura con un "estilo" propio. Ésta se encuentra en tensión con la literatura europea, la literatura norteamericana y el capitalismo y sus condiciones de mercado. El colonialismo cultural y económico que constituye a la literatura latinoamericana, afirma Libertella, es lo que establece la diferencia material de América Latina, en el triángulo de intercambio con el mundo. Diferencia que ha provocado "una expresión americana" que se lee en la obra de Fray Servando, de Martí, Sarmiento, de Whitman, de Darío, de Mariátegui, de Martínez Estrada, de Lezama Lima”, una genealogía cuya procedencia, desde el trópico hasta el Río de la Plata, deja al desnudo no una literatura en crisis de gestación, sino una literatura ya "gestada" (Libertella, 2008) por la dispersión, el estallido, la constelación; en suma, un conjunto de procedimientos literarios que 
Libertella lee en Farabeuf de Salvador Elizondo, Sebregondi retrocede de Osvaldo Lamborghini, The Buenos Aires Affair de Manuel Puig, La orquesta de cristal de Enrique Lihn, El mundo alucinante de Reinaldo Arenas y Cobra de Severo Sarduy. ${ }^{20}$ En la línea de reflexión de Pedro Enríquez Ureña y de Jorge Luis Borges, al escritor cavernícola le pertenece toda la literatura y esa "nueva escritura" no es un fenómeno, una resultante o un tema del continente sino una escritura que "se concibe-críticamente- como latinoamericana" y que exhibe en la artificialidad de los textos y las marcas del trabajo literario, una práctica que antinaturaliza la escritura y la separa del juego natural de comunicación exasperando su calidad de trazo, de sistema escrito" (Libertella, 2008).

El modelo americano de la tradición para esa nueva escritura crítica latinoamericana es, según Libertella, La expresión americana (1957) de José Lezama Lima, debido a que, a partir del dispositivo lezamiano, ya no es posible pensar la crítica separada de la ficción y de la teoría literaria. El método barroco que Lezama despliega en La expresión americana, convertido en método crítico y en progra$\mathrm{ma}$, articula lo que Libertella propone como escritura latinoamericana en tanto potencia transformadora de lo existente, liberada de los modelos europeos, norteamericanos y del mercado capitalista;

${ }^{20}$ Entre los procedimientos que Libertella señala como la escritura del cavernícola se lee la "sintaxis retorcida" y el sentido de "una múltiple filigrana" de Sebregondi retrocede (1973) de Osvaldo Lamborghini; "el apegarse compulsivamente a su propia letra" y la narración infinita de un instante de Farabeuf (1965) de Salvador Elizondo; "el gusto por interferir la narración de hechos novelísticos" mediante metamorfosis y travestismos de Cobra (1972) de Severo Sarduy; la prescindencia de un único narrador en The Buenos Aires affair (1973) de Manuel Puig, la artesanía de una novela que hace "explícita su trabajo sobre otros textos" como El mundo alucinante (1970) de Reinaldo Arenas, y la parodia que hace "trizar" los elementos de una tradición culta -la belle époque- para mostrar "un tipo de artesanía acostumbrada a revolver indiferente en las escrituras de cualquier época y lugar" de La orquesta de cristal (1976) de Enrique Lihn. 
una textualidad que mientras se tiende entre lo universal y lo criollo y pone en discusión el evolucionismo crítico, exhibe maniobras de condensación y desplazamiento convirtiendo a la "imagen" en la depositaria del sentido. ${ }^{21}$ Lo nuevo que Libertella recorta y teoriza en Nueva escritura en Latinoamérica se inscribe en esa genealogía, textos que, en coexistencia con una literatura que se sostiene en la fantasía de una evolución crítica, retoman el mito griego de la astucia y simulan "operar en el cuerpo social escondida en un caballo de Troya" ( Libertella, 2008); allí, en las sombras, la nueva escritura espera, y ajena a los rápidos efectos de consagración del mercado, dice Libertella, "pica, graba, talla-compulsivamente en las cuevas" (2008), no para recuperar a Helena sino para protegerse -herméticamente- de las instituciones, del mercado, para, al mismo tiempo, sigilosamente, impregnarlas, desplazarlas.

¡Cavernícolas!, ficcionaliza el conjunto de maniobras teóricas y críticas de Nueva escritura. Los relatos constituyen el momento de afirmación del pro-yecto libertelliano iniciado en El camino de los hiperbóreos, cuya maduración se produce durante la década de los años setenta, cuando Libertella vive entre Iowa y Nueva York (Ver López, 2016) con latinoamericanistas y escritores de todo el

${ }^{21}$ El original y complejo texto de 1957 de Lezama Lima construye la Imago -cultural, artística, política- de Latinoamérica, desde el siglo XVII, el barroco de la Contra-conquista, hasta el siglo XX. Imágenes, eras imaginarias en las que interviene la memoria, siempre creadora, espermática, del "sujeto metafórico" que, con "su fuerza revulsiva", procesa las entidades de la cultura, de la historia y del paisaje, produciendo "la metamorfosis hacia la nueva visión" (215) para de ese modo, formar e inventar un tipo de imaginación. En La expresión americana, Lezama hace lo que propone críticamente: el sujeto metafórico y "metamórfico"(Yurkievich, 2002: 815) mira una forma en devenir, con una sencilla hermenéutica la reconstruye y la ordena construyendo una "visión histórica" (213) que le otorga "el contrapunto o tejido entregado por la imago", así, la imagen es la construcción de una ficción debido a que "la técnica histórica no puede establecer el dominio de sus precisiones" (217). Lezama Lima, José. "La expresión americana”, (Lezama Lima, 1988). 
mundo, mientras publica ensayos y relatos en revistas literarias. ${ }^{22}$ Después vino el regreso a Argentina y su participación en la revista Literal (1973-1977) junto a Germán García, Osvaldo Lamborghini, Luis Gusmán y otros escritores, lo cual implicó el impregnarse de una "flexión literal" que sobreimprime su escritura.

El "juego de la novela aplastada" en los tres relatos de ¡Cavernícolas! deshilacha la pretendida representación de la lengua así como el supuesto poder del portavoz o del escribiente ya que perturba y des-localiza, en tanto parodia, las crónicas de Indias, el lenguaje como institución (y con ello, el lenguaje del conquistador) y la lógica de los imperios frente a las riquezas de la humanidad. Fernando de Magallanes, Jorge Bonino y Rassam, son las figuras en torno a los cuales el cavernícola, sujeto metamórfico y metafórico, articula los procesos de digestión de la nueva escritura crítica y transforma lo existente apelando a la ficción y a la invención de formas en devenir que exhiben las huellas de ese amor por la letra antigua.

El camino de los hiperbóreos, Nueva escritura en Latinoamérica y iCavernicolas! conforman entonces los nudos visibles de un proyecto que articula los modos de concebir la literatura de Libertella; un "proceso" del leer, del escribir y del re-escribir que implica el pararse frente a los textos, a la tradición, a la biblioteca y proponer una poética y una política de la lengua que se piensan como lugares de resistencia y de reflexión crítica. La literatura "es un papel que viene de otros papeles" (Libertella, 1990) y un libro tomado al azar "supone toda la biblioteca" (2003) escribe Libertella en En-

${ }^{22}$ Nueva escritura reescribe artículos ya publicados en las revistas Hispamérica y Dispositio, entre 1974 y 1976. Lo mismo sucede con ;Cavernicolas!, "Nínive" fue publicado como "Nínive, 1853", en 1982, en la Revista de la Universidad de México; "Historia de historias de Antonio de Pigafetta" fue publicado como "La leyenda de A. Pigafetta", en 1985, en Nueva narrativa Hispanoamericana 18161981, Historia y Antología, La generación 1939 en adelante. Argentina, Paraguay, Uruguay, un texto compilado por Ángel Flores. 
sayos o pruebas sobre una red hermética y en La librería argentina respectivamente teorizando lo que su poética ha desplegado desde su ingreso al espacio literario.

Ese modo de hacer literatura patentiza otro rasgo de su poética: el pliegue y repliegue de la escritura de la huella que en su adelgazamiento exhibe una conjetura sobre la página en blanco. En los sucesivos textos cuyas publicaciones se realizan mientras Libertella está vivo, el blanco va ocupando un espacio de magnitudes similares a la letra escrita y el texto se adelgaza. Dibujos, afiches, fotos, imágenes provenientes de enciclopedias y revistas, se desplazan a dibujos realizados por el artista plástico Eduardo Stupía, a pedido de Héctor.

Los textos narrativos El camino de los hiperbóreos (Premio Paidós, 1968), Aventura de los miticistas (Premio Monte Ávila, 1971) y personas en pose de combate (1975) presentan más de ciento cincuenta páginas y una letra apretada. En cambio, Nueva escritura en Latinoamérica (1977) y los textos siguientes, ;Cavernicolas! (1985), El paseo internacional del perverso (Premio Juan Rulfo, 1986), Ensayos o pruebas sobre una red hermética (1990), Patografeia. Los juegos desviados de la Literatura (1991), Memorias de un semidios (1998), El árbol de Saussure (2000), La librería argentina (2003), Diario de la rabia (2006), El lugar que no está ahi (2006), La arquitectura del fantasma. Una autobiografía (2006), con excepción de Las sagradas escrituras (1993), insisten en las singularidades de la brevedad, en la marca de la grafía en el blanco de la página, en el espacio en blanco, en el vacío del blanco que se llena de huella de textos del escritor y de textos que se escriben en "proceso". Libertella muere en 2006, sus textos póstumos, Zettel (2008), La leyenda de Jorge Bonino (2010), A la santidad del jugador de juegos de azar (2011) también exhiben esa poética. 


\section{Tres}

La posición de Libertella como "hiperbóreos" lleva a repensar las categorías que el filósofo de El anticristo desenmascara, ya que el diálogo de Libertella es con Nietzsche y no con otro pensador de la filosofía. ${ }^{23}$ No es forzado ubicar a Libertella dentro de esa genealogía cuando recorta su pro-yecto de la Literatura: la lengua, el sujeto, la forma, el tiempo, el espacio, son trastornados por la escritura libertelliana mediante una poética que muestra, en la medida que difiere y se disemina, la construcción artificial de los conceptos y sistemas.

En "Teoría de la caverna. Los restos de un futuro que vuelve" de El efecto Libertella, Raúl Antelo lee la poética de Libertella bajo la impronta de "lo informe" -noción que toma de Georges Bataille- que tiene el signo de Mallarmé y de una respuesta ligada a la filosofía de Nietzsche que no se detiene frente "a la muerte de Dios, sino al vacío ontológico que ella suscita" (Antelo, 2010). Siguiendo el ensayo de Derrida (2013), "La forma y el querer-decir", Antelo señala que el concepto de forma "es la presencia misma" de la metafísica e

informe no es sólo un adjetivo con determinado sentido sino un término que sirve para desubicar, exigiendo generalmente que cada cosa tenga su forma. Lo que él designa carece de derechos en

${ }^{23}$ La metafísica es la historia del olvido, escribe Nietzsche, el lenguaje, el ser, el sujeto, etcétera, son nociones construidas para imponer un orden al devenir del caos; pero, al entrar en el mundo de la lógica, esas pseudoverdades se postulan como verdades últimas, olvidando su origen. Es en ese olvido que Nietzsche martilla debido a que esa construcción -divinizada, verdadera- es la que le permite a los metafísicos generar la idea de un mundo trascendente que Nietzsche provoca con su dictus "nosotros somos hiperbóreos", es decir, nosotros pensamos desde una perspectiva que difiere de la "metafísica" (incluso cuando se la piensa dentro de sus propias categorías y no es fácil salir de ella). 
todo sentido y se hace aplastar por todas partes como una araña o un gusano de tierra. En efecto, para que los académicos estén contentos sería necesario que el universo tomara forma. La filosofía entera no tiene otro fin: se trata de otorgar una levita a lo que es, una levita matemática. En cambio, afirmar que el universo no se parece a nada y sólo es informe es lo mismo que decir que el universo es algo parecido a una arańa o un escupitajo (Bataille apud Antelo, 2010).

Si como dice Alain Badiou, "el arte es la formalización secundaria del advenimiento de una forma hasta entonces informe" (2010), Antelo se pregunta cómo desplazar -“desubicar" dice Bataille- el concepto de forma de los griegos que impone "una indeseable sumisión del sentido a la mirada” (2010), cómo asumir la "potencia negativa de su presencia” (2010). La elipsis neobarroca, la circularidad descentrada, el anacronismo, sostiene Antelo, dan lugar a otra comprensión del arte como una "forma des-plazada" en la que la huella anuncia y recuerda "a su otro" (2010) ya que el salirse del sistema de oposiciones y el abandono del binarismo, "vuelve posible la forma -lo literal- desde lo irreductible de su exceso" (2010).

Antelo centra su lectura en Nueva escritura en Latinoamérica y en la revista Literal (tanto los textos que Libertella publica en la revista como en su manifiesto, "La flexión literal") y lee en esos textos, el neobarroco, la circularidad descentrada y el anacronismo libertelliano, operaciones de descentramiento que ya se articulan en El camino de los hiperbóreos cuya estructuración -en el comien$z o-$ exhibe la marcas del vestigio de lo informe, de la forma de una cierta no-presencia (aunque es difícil salirse de ella) que retiene, anuncia y recuerda, la huella de lo otro. Con el fin de producir la 
diferencia ${ }^{24}$ exigiendo un conjunto diagramático de lecturas que no se dejan reducir a un sentido único, a una verdad, a una mirada lineal, sino se abre a una textualidad inestable que no cesa de significar y, como tal, requiere otro modo de leer y de mirar y que, aun dejándose penetrar por el sentido y la interpretación, se mantiene en constante proceso de producción, de envíos y reenvíos desjerarquizados en ese mosaico de fragmentos y lenguajes descentrados que pueden leerse en la primera novela editada de Héctor Libertella y, en adelante, en los siguientes textos publicados.

La teorización de ese asedio a la forma de la metafísica, Libertella se lee en Ensayos o pruebas sobre una red hermética (1990):

¿Los locos son herméticos? Desde la literatura hay pocos caminos para rastrear el pasado de esa pregunta. La filología, quien sabe, tal vez ella podrá exhumar las fuentes que llevan desde y hacia el cuerpo hermético. Aquí es posible englobarlo todo, efectivamente: Corpus Hermeticum, Séfer Yetsirá o cábala negra, mística cristiana, barroco, cábala clásica. La oposición ilustrada a un saber y al Logos o forma única de la Razón. Hoy habrá que agregar, graciosamente, la homeopatía (la impensable gota diluida de Hahnemann), la alquimia y las alternativas del psicoanálisis: aquellas negatividades de origen puramente artesanal que prometen el oro, la piedra filosofal o la cura, por distintas vías o desvíos. Actividades, todas ellas, que no se reconocen en la ideología del círculo sino en el descentramiento que es doscentramiento. ¿Cómo intervendrá aquí el loco? ¿El escritor loco se descentra o se doscentra? ¿Cómo funcionan las formas de esa geometría haciendo eco en las formas de su retórica? ¿Y cómo se comportará ese universo de signos en

${ }^{24}$ La huella es la diferencia y es anterior a todo lo que se denomina signo (significado/significante, contenido/expresión); al ser la diferencia, la formación de la forma permite la articulación de los signos entre sí como texto fónico o gráfico, como habla y como escritura y también como oposición a la esencialidad de la metafísica (ver Derrida, 1971: 81-83). 
relación con el mercado y/o las pautas de una comunicación literaria eficaz, en posición dialógica?; cuando uno habla en dos.

REPRESIÓN = SALUD En su momento constitutivo o genético, ¿no habrá sido la antigua escritura hermética (la egipcia) un modo político de organizarse para pasar un mensaje clandestino y sobrevivir? (Libertella, 1990; las itálicas son mías).

El hermetismo es una respuesta a la determinación del eidos o la morphé. Las literaturas herméticas, como las denomina Libertella, en su forma informe, resisten a la interpretación por medio de un lenguaje y un signo escrito que problematiza no sólo los conceptos metafísicos sino también toda marca convertida en ley como los estereotipos de las instituciones, el fascismo de la lengua, las leyes del mercado. Esas escrituras hacen estallar, como la poética libertelliana, los conceptos, las formas, los sistemas anquilosados de la literatura. En esa dirección, Libertella coloca los procedimientos del barroco en el centro de operaciones de ese proceso de descentramiento que va a producir las fugas y los extrańamientos.

A la estrategia del caballo de Troya que propone en Nueva escritura en Latinoamérica, se suma la del cerrojo de la hermesis, sin que ello implique la imposibilidad de circulación de esas literaturas (Hermes es también el dios del comercio y su lógica las impregna). "El árbol hermético de las vanguardias", que propone Libertella, su genealogía y representantes, es la "fuente brotante" (1990) de la literatura latinoamericana que exhibe una "actitud de-volutiva de la propia lengua” (1990), de repliegue hacia el pasado para buscar todas las potencias de la enunciación para luego, empastar, parodiar, pastichar, un texto o insistir en las maniobras del "silencio o el palabrerío" (1990). El gesto de vanguardia sigue siendo el de perturbar la biblioteca, retomar sus huellas en un ir hacia el pasado para producir un texto otro. De allí que la idea de vanguardia de Libertella postule no lo que está más adelante si no lo está más 
íntimo, lo que se digiere en las cuevas para luego excretar, como escribe en Nueva escritura en Latinoamérica, un tejido de huellas.

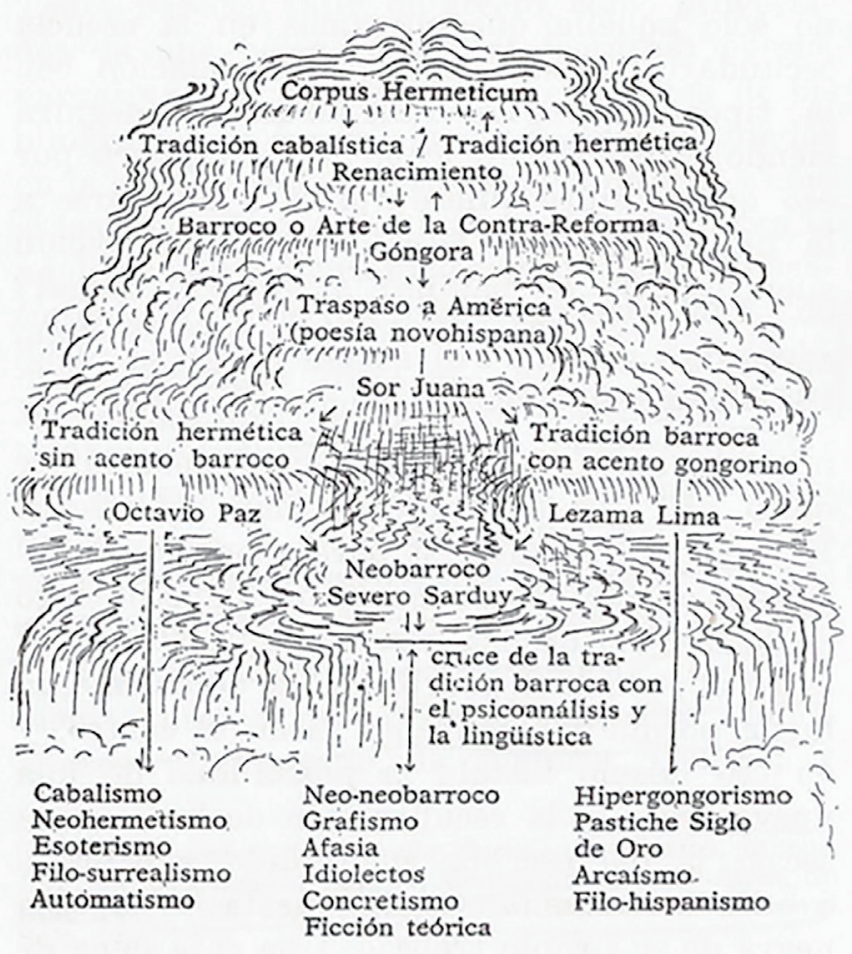

"La fuente brotante"25

"Es el río de letras el que se va, hecho texto" (1990) dice el verso de Octavio Paz que Libertella cita para desplazar escritura de la huella, de escritura metafísica. El río, el flujo y la marca de una grafía y de una literatura en la que se lee no sólo lo que está

25 "La fuente brotante" es un dibujo del artista plástico Eduardo Stupía a pedido de Héctor Libertella, en Ensayos o pruebas sobre una red hermética, 1990. 
en la página sino también lo que no está, el vacío lleno, porque la hermesis no es sólo producto del repliegue de la literatura, de la literatura hecha de literatura, sino también de la posición crítica del escritor frente a la literatura, al recorte de su programa literario, a sus modos de leer y a su producción escrituraria.

\section{Uno en dos}

Tanto en los textos narrativos como ensayísticos Libertella cruza ficción, crítica y teoría, "como escritor hace eso que como teórico dice” escribe Martín Kohan (2010) siendo la ficción teórica la singularidad de su escritura que se inscribe de una y otra manera desde El camino de los hiperbóreos.

"Alguien, alguna vez, pensará en Nietzsche pero escribirá Sade [...] el texto teórico podrá ser portador de la ficción y la reflexión semiótica tejerá la trama del poema” (1990), es la cita de Osvaldo Lamborghini (1973) que Libertella transcribe para aproximarse a esa forma de escritura que teoriza en Ensayos o pruebas sobre una red hermética, desde la perspectiva libertelliana, la ficción crítica provoca y perturba al lector ya que "un empedrado de conceptos le prepara un efecto de cuento" aunque, al mismo tiempo, lo libera de la cárcel del signo porque permite una lectura del texto en cualquier dirección, en infinitos sentidos.

La inextricable relación entre teoría, crítica y ficción en textos narrativos, críticos y teóricos, se lee, en la literatura argentina, en los textos de Macedonio Fernández y en los de Jorge Luis Borges; Libertella la lee en los escritores latinoamericanos en Nueva escritura; Nicolás Rosa la consigna en "la novela familiar de la crítica literaria” argentina, siendo él, Ricardo Piglia y Héctor Libertella, algunos de sus representantes. ${ }^{26} \mathrm{La}$ cita de Lamborghini señala que

${ }^{26}$ Nicolás Rosa indica que el antecedente excelso de esta modalidad de escritura, que emparienta con la ciencia-ficción, no es H.G. Wells sino Freud. 
la ficción crítica formaba parte del programa del grupo Literal. Asimismo, es lo que proponen los telquelianos, en los sesenta, al pensar la escritura a partir de la idea de texto y la consideración del lenguaje y el rol del lector. La ficción crítica ha recibido distintas denominaciones así como la noción de dominante, de hibridación, de mezcla y de contaminación, persisten en sus clasificaciones.

Al considerar las operaciones de su poética, la ficción crítica o teórica que hace y propone Libertella guarda menos relación con el quantum de teoría y crítica que entra en la ficción y el de la ficción que entra en la teoría y en la crítica (en suma toda construcción escrituraria es una ficción) que con la posición "crítica" del escritor que construye la escritura e inscribe la grafía. El hiperbóreo, el cavernícola, el hermético, es un escritor de ficción teórica por su metaposición frente a la literatura y a los lenguajes y, en esa dirección, la ficción crítica es una práctica del lector-escritor que escribe desde una biblioteca, haciendo visibles sus lecturas.

En el arco que va desde El camino de los hiperbóreos a El árbol de Saussure (2000) se pueden leer las torsiones que Libertella ha ido produciendo en su asedio a los artificios literarios: 1) los procedimientos que trastornan la figura de narrador, desde los desvíos de la voz de la enunciación hasta su mortificación mediante la articulación de apócrifos y citas falsas que aparecen en El árbol de Saussure; 2) los desplazamientos de las categorías de tiempo y espacio, el espacio se descentra o "doscentra", ${ }^{27}$ el tiempo se percibe como temporización; ${ }^{28}$ 3) la exhibición desaforada del fragmento

${ }^{27}$ El diálogo con los conceptos del neobarroco y con Severo Sarduy se visibilizan en El árbol de Saussure: "UNO DOS ¿Cómo resuelve Uno esa paradoja? ¡Se descentra o se doscentra? ¡Se instala en el centro perfecto galileico o es elíptico y deforme como un Kepler? Y algo más: ¿cómo se comportan esas geometrías haciendo eco en la forma de su retórica? ¿Su manera de conversar es oval [...]?” (32).

${ }^{28}$ Considero que la poética de Héctor Libertella se aleja de las significaciones de futuro, pasado y presente que sugiere la concepción vulgar del tiempo y, por 
como "proyección inmediata de lo que no acaba"; 4) las figuraciones del arte pop de El camino de los hiperbóreos desplazadas a collage entre dibujo, imágenes y escritura; 5) el cruce entre escrituras fonéticas y no-fonéticas; 6) los injertos, los desvíos y las fugas en el laboratorio (cocina) de las formas; 7) los espacios en significancia del juego con el blanco y la idea de un vacío lleno; 8) la literatura hecha de literatura y de otros lenguajes; 9) las marcas visibles e invisibles del encuentro entre lectura y escritura, las huellas de textualidades propias y de otros escritores; 10) la lectura crítica como motor de la confabulación e imaginación narrativa y teórica. El árbol de Saussure tematiza lo que Libertella viene horadando desde su primera novela: ${ }^{29}$ la desaparición del signo de la presencia, el árbol -paradigma de la lengua y de la metafísica de la presencia- ya no liga nada con nada. Todos los fragmentos lanzados en una tirada. Entre la apertura con el epígrafe apócrifo de Winfried Hassler y el último capítulo del texto, "El futuro ya fue", El árbol

lo tanto, propongo el concepto de temporalidad como el "advenir presentando que va siendo sido"(Heidegger, 2004: 351-8).

${ }^{29} \mathrm{El}$ árbol, en la poética de Héctor Libertella, es la figura que permite el desplazamiento, el "tránsito hacia". El camino de los hiperbóreos cierra con la imagen del árbol "cósmico" como una figura que permite la apertura hacia otras posibilidades; en El árbol de Saussure, además de una toma de posición frente a las discusiones teóricas sobre el lenguaje (la filosofía, el psicoanálisis y las teorías del lenguaje), confluyen un entramado de lecturas y escrituras tales como el estudio de Libertella sobre las literaturas herméticas, la hermesis, el lugar de la literatura y su resistencia frente al mercado. También las lecturas críticas de escritores latinoamericanos, cuyas especulaciones se tematizan en El árbol de Saussure como La orquesta de cristal y Por fuerza mayor de Enrique Lihn (la hipertrofia de la retórica, el disfraz de la cháchara, el loro, el silencio o el palabrerío) y los textos de Octavio Paz como El mono gramático, texto con el que dialoga en torno a las figuraciones del árbol: "el árbol que digo no es el árbol que veo, árbol no dice árbol, el árbol está más allá de su nombre [...] realidad más allá de los signos [...] una realidad que está más allá de los nombres, más allá de la palabra realidad' (Paz, 1998: 49). 
de Saussure postula que las cosas "están abandonadas a su ser asî" (97) y la literatura es, fue, será, sería, así tachado, "la memoria retrospectiva de lo que vendrá” (99). Un artificio que enfantasma la figura del escritor que, en su condición camaleónica y de aparente desaparición en el flujo de la letra, marca en la grafía, en el trazo, el mensaje clandestino que se construye, crítico, en el leer, en ese dictus libertelliano de que la lectura es el "acomodar los blancos al ojo" (2000).

\section{Bibliografía}

Antelo, Raúl, 2010, “Teoría de la caverna. Los restos de un futuro que vuelve", en El efecto Libertella, Marcelo Damiani (ed.), Rosario, Beatriz Viterbo.

Barthes, Roland, 1987, El susurro del lenguaje, Barcelona, Paidós. ,2005, La preparación de la novela, Buenos Aires, Siglo XXI. , 1997, S/Z, Madrid, Siglo XIX.

,2003, "Texto (teoría del)", en Variaciones sobre la escritura, Buenos Aires, Paidós.

Blanchot, Maurice, 1994, El paso (no) más allá, Barcelona, Ediciones Paidós.

, 2008, La conversación infinita, Madrid, Arena Libros.

Borinsky, Alicia, 1975, "Re-escribir y escribir: Arenas, Menard, Borges, Cervantes, Fray Servando", Revista Iberoamericana, núm. 92-3, julio-diciembre.

Burucúa, José Emilio, 2003, Historia, arte, cultura. De Aby Warburg a Carlo Ginzburg, Buenos Aires, FCE.

Cippolini, Rafael, 2016, "Libertella: reversiones de éditos y libros inventados", en Libertella/Lamborghini. La escriturallimite, Silvana López (ed.), Buenos Aires, Corregidor. 
Compagnon, Antoine, 1979, La seconde main. Ou le travail de la citation, París, Éditions du Seuil.

Derrida, Jacques, 1971, De la gramatologia. Buenos Aires, Siglo XIX.

, La diseminación, 1997, Madrid, Editorial Fundamentos.

, 2013, "La forma y el querer-decir", en Márgenes de la filosofía, Madrid, Cátedra.

Didi-huberman, Georges, 2011, Ante el tiempo. Historia del arte y anacronismo de las imágenes, Buenos Aires, Adriana Hidalgo.

Estrin, Laura, 1994, "Libros en pose de combate. Sobre Las sagradas escritura y otros libros de Héctor Libertella", Espacios, FFyL. UBA, núm. 14, Agosto.

Fernández, Macedonio, 1987, Relatos. Cuentos, Poemas y Misceláneas. Obras Completas, vol. 17, Buenos Aires, Corregidor. , 2007, Museo de la novela de la Eterna, Buenos Aires, Corregidos,

Heidegger, Martín, 2004, El ser y el tiempo, Buenos Aires, FCE.

Jitrik, Noé, 1993, "Rehabilitación de la parodia”, en La parodia en la literatura latinoamericana, Roberto Ferro (coord.), Buenos Aires, ILH/FFyL/UBA.

,2000, Los grados de la escritura, Buenos Aires, Manantial.

Kohan, Martín, 2010, "La pasión hermética del crítico a destiempo", en El efecto Libertella, Marcelo Damiani (ed.), Rosario, Beatriz Viterbo.

Kristeva, Julia, 2001, Semiótica I, Madrid, Fundamento.

Lacoue-labarthe, Philippe y Jean-luc Nancy, 2012, El absoluto literario, Buenos Aires, Eterna cadencia.

Lamborghini, Osvaldo, "La intriga”, Literal, núm. 1, 1973. 
Lezama Lima, José, 1988, Confluencias, La Habana, Editorial Letras Cubanas,.

Libertella, Héctor, 1968, El camino de los hiperbóreos, Buenos Aires, Paidós.

, 1972, Aventuras de los misticistas, Caracas, Monte Ávila Editores S.A.

, 1985, ¡Cavernícolas!, Buenos Aires, Per Abbat.

, 1990, Ensayos o pruebas sobre una red hermética, Buenos Aires, GEL.

, 1991, Patografeia. Los juegos desviados de la Literatura, Buenos Aires, Grupo Editor Latinoamericano.

, 1998, Memorias de un semidiós, Buenos Aires, Perfil.

, 2000, El árbol de Saussure, Buenos Aires, Adriana Hidalgo.

, 2003, La Librería Argentina, Alción, Córdoba,

, 2006, La arquitectura del fantasma. Una autobiografía, Buenos Aires, Santiago Arcos.

,2006, El lugar que no está ahí, Buenos Aires, Losada.

,2009, Zettel, Letranómada, Buenos Aires.

, 2008, Nueva escritura en Latinoamérica, Buenos Aires, El andariego.

, "Héctor Libertella. Carta desde Nueva York", en Libertellal Lamborghini. La escriturallimite, Silvana López (ed.), Buenos Aires, Corregidor, 2016.

Lihn, Enrique, 1976, La orquesta de cristal, Sudamericana, Buenos Aires.

, 1980, El arte de la palabra, Barcelona, Editorial Pomaire.

LITERAL, 2011, García, Germán [et al.], Buenos Aires, Biblioteca nacional. 
López, Silvana, 2016, "Héctor Libertella. Carta desde Nueva York", en Libertella/Lamborghini. La escriturallimite, Silvana López (ed.), Buenos Aires: Corregidor, 2016.

Nietzsche, Friedrich, 2011, El anticristo. Maldición sobre el cristianismo, Madrid, Alianza Editorial.

Paz, Octavio, 1998, El mono gramático, Barcelona, Galaxia Gutemberg.

Riffaterre, Michel, 1980, "La Trace de l'intertexte", La Pensée, París, núm. 215.

Rosa, Nicolás, 1999, "Veinte años después o "la novela familiar de la crítica literaria”, en Políticas de la crítica. Historia de la crítica literaria en la Argentina, Nicolás Rosa (ed.), Buenos Aires, Biblos.

Saavedra, Guillermo, 1993, La curiosidad impertinente. Entrevista con narradores argentinos, Rosario, Beatriz Viterbo.

Said, Edward, 1985, "A meditation on Beginnings", Beginnings, Intention and Method, Nueva York, Columbia University Press.

Sarduy, Severo, 2011, El barroco y el neobarroco, Buenos Aires, El cuenco de Plata.

Warburg, Aby, 2010, Atlas Mnemosyne, Martín Warnke (ed.), Madrid, Akal.

Yurkievich, Saúl, 2002, "La expresión americana o la fabulación autóctona”, Revista Iberoamericana, vol. LXVIII, núm. 200. 